Forthcoming in Catherine Cassell \& Gillian Symon (2012) The Practice of Qualitative

Organizational Research: Core Methods and Current Challenges, London: Sage

\title{
Participatory Visual Methods
}

\author{
Russ Vince and Samantha Warren
}

\section{Introduction}

This chapter discusses drawing, and participant-led photography - as approaches that explicitly involve research respondents in the co-creation of qualitative data. Through these examples we demonstrate the utility of employing visual methodologies in the investigation of organizational life. We begin with a brief overview of the development of visual studies in organizational research before discussing ways in which drawings and participant-led photography have been used in the field. This sets the scene for two examples from our own research. The first outlines how Russ used drawing as a method to generate emotional data about organizational change (Vince and Broussine 1996) and the second describes Samantha's use of participant-led photography to produce data about the importance of personal space in 'hot-desk' workplace environments (Warren 2006). We then extend this discussion by addressing what we see as two of the key challenges in participatory visual research methodology: ethics and the analysis of visual data. We conclude with some personal reflections on the use of participatory visual methods in our research.

We focus on participatory visual methods for two reasons. First, in our opinion, involving research participants in the generation of data about their organizational lives - beyond traditional 'question and answer' techniques - is of growing importance given an increasing sensitivity to the ethics of the qualitative research process as it matures as an established methodological paradigm (Gottlib-Conn 2008). As academic researchers, we gain from understanding the experiences of those we research, but in comparison these people may receive relatively little in return. The people who are kind enough to help us with our research receive little or no 'right of reply' to what we say about their worlds (Wray-Bliss 2003; Brewis and Wray-Bliss 2008). Given the rise in scrutiny by institutional research ethics committees (Gottlib-Conn 2008), and greater demands by research funding councils to demonstrate the 'impact' of our research on stakeholder communities beyond academia, we believe that involving research participants remains a high priority for qualitative research and that visual methods offer excellent opportunities for this. 
Second, methodological commentary on the analysis of 'pre-existing' visual materials is far more developed than that concerned with generating visual material as part of the research process (see for example van Leeuwen and Jewitt 2001; Kress and van Leeuwen 2006). However, in this chapter we are making a distinction between methods that enable research participants to express themselves visually, such as asking them to create an artefact, draw, recount their dreams or take photographs; and the researcher's analysis of 'found' organizational images, such as brochures, advertisements, websites, films etc which does not usually overtly involve participants (Warren 2009). It is the former variant of visual methodology that we are concerned with in the following discussions.

\section{Overview: visual organization studies}

The inclusion of this chapter in the 'core methods of qualitative inquiry' section of this volume is an indication of the rising interest in visual methods by organizational researchers. Long established in anthropology and sociology, visual methods either utilise processes of visualisation to generate data, or take visual artefacts as their unit of analysis (Warren 2009). Despite a provenance of several decades in the social sciences, visual studies of organizational life have been slow to appear (Strangleman 2004), and those that have, have largely been undertaken: by sociologists of work rather than organization or management scholars (eg; Halford 2004; Harper 1984; Strangleman 2008); or from within the fields of education and healthcare research (Prosser 1998; Morgan et al 2009). In recent years there has been a steady growth in the visual within organization and management studies itself, as evidenced by the formation of inVisio, the International Network for Visual Studies of Organization in 2007, the first journal special issue on 'Visual Perspectives on Accounting' (AAAJ 2009), the $28^{\text {th }}$ Standing Conference on Organizational Symbolism's 2010 conference theme of 'Vision' (SCOS 2010) and the commissioning of a special issue on visual qualitative research by the journal Qualitative Research in Organizations and Management due to be published in 2012. Elsewhere, in her commentaries on the current state of the field, Samantha gives a variety of reasons for this surge in interest (Warren 2008, 2009). These include a cultural predisposition towards 'the aesthetic' in contemporary advanced consumer society that generates an image-saturated society, an epistemological turn towards the material and aesthetic in organization studies; and the practical fact that digital technologies have made the collection, storage, manipulation and display of images a routine affair, which has democratized photography and increased its reach both as a social practice and accessible research method.

In organization studies, examples of visual research include semiotic and critical visual analysis of organizationally produced images, such as annual reports (Davison, 2009 (Davison and Skeratt 2007); advertisements (Borgerson and Schroeder 2002; Schroeder 2002; and more classically Williamson 1978), websites (Kivinen 2006; Cho et al 2009), 
promotional literature (Hancock 2005; Belova 2004) and representations of work and organization in popular media (Guthey and Jackson 2005; Hancock 2008; Bell 2008; McDonald 2009). Other research has considered the importance of architecture and the aesthetico-symbolic dimension of corporate life (Dale and Burrell 2003; Gagliardi 1990; Jackson and Carter 2000) and indeed the visual manifestations of organizational death (Bell 2010; Strangleman 2009). A further branch of research has employed visually oriented methods to generate data about organizational phenomena including employee identities (Shortt 2010; Warren and Parker 2009), fun at work (Warren and Fineman 2007), leadership (Wood and Ladkin 2007), strategy (Meyer 1991), child and immigrant workers (Bolton et al 2001, Gallo 2002), change (Vince and Broussine 1996), and process re-engineering (Buchanan 2001).

It is this last variant of visual methodology that specifically concerns us in this chapter. As noted above, we consider two participatory visual methods - drawing and participant-led photography - and it is to these discussions that we now turn.

\section{Two Worked Examples}

\section{Example One: Drawings}

The use of drawings in management and organization studies can be traced back to the late 1980's. One of the key early examples is Shoshana Zuboff's (1988) book In the Age of the Smart Machine: the Future of Work and Power. Professor Zuboff asked clerical workers to draw pictures showing how they felt about their jobs before and after the installation of a new computer system. These drawings helped staff to articulate feelings that had been implicit and were hard to define. In terms of understanding and developing the method, a key paper was published in Organization Science (Meyer, 1991) called 'visual data in organizational research'. Meyer acknowledges that 'visual instruments seem uniquely suited to... efforts to build theory and research focusing on human awareness, interpretation and consciousness' (Meyer, 1991: 232). There are a number of published papers that can provide the researcher with discussions and/or examples of this method in organization studies (Vince, 1995a; Holliday, 2000; Kearney and Hyle, 2004; Strangleman, 2004; Stiles, 2004; Bryans and Mavin, 2006; Bagnoli 2009). The method has been used by researchers interested in revealing the links between individuals' real and imagined idea of 'the organization' they work in (Hutton et al, 1997) and the organizing dynamics and forces that shape and are shaped by their interpretations and actions. Drawings can provide 'a succinct presentation of participant experiences'; they offer opportunities to engage overtly with researcher bias; and the approach triangulates well with other qualitative data generation methods (Kearney and Hyle, 2004).

Here, we discuss an example of Russ's research that used drawings as a method to study emotions, relations and politics associated with change processes in public sector 
organizations (Vince and Broussine, 1996). The starting point of this research 'is the belief that change depends as much on comprehending and managing emotional relatedness as it does on employing rationality and logic to solve problems' (p. 4). In other words, asking individuals to produce drawings to generate visual data (in much the same way as individual interviews generate verbal data) allowed Russ and his colleague to look at the intersection between the emotional and the rational in processes of change.

The usefulness of this research approach is that drawings tend to portray individual emotions effortlessly, since there are often unexpected and enigmatic aspects to an image. This assumption rests on a conceptual grounding in psychoanalysis whereby the emotional or 'pre-rational' contents of the mind are revealed through images, including dreams as well as drawings (see Broussine 2008, Rose 2007 ch.6 for an introduction to these ideas). However, their real value in research is in the way they can reveal aspects of collective emotional experience and knowledge about a specific work context. Asking a group of participants to draw their team or organization is an invitation to generate multiple interpretations and to promote dialogue over the collective and contested meaning of individuals' images. This inevitably raises questions about the power relations that shape both experience and interpretation (Sievers 2008).

The research by Vince and Broussine (1996) involved a total of 86 managers (49 middle managers/ 37 senior managers) from six organizations (4 Local Government/ 2 Health Service). Each participant produced a drawing, some of which are reproduced below (Figure 1). 

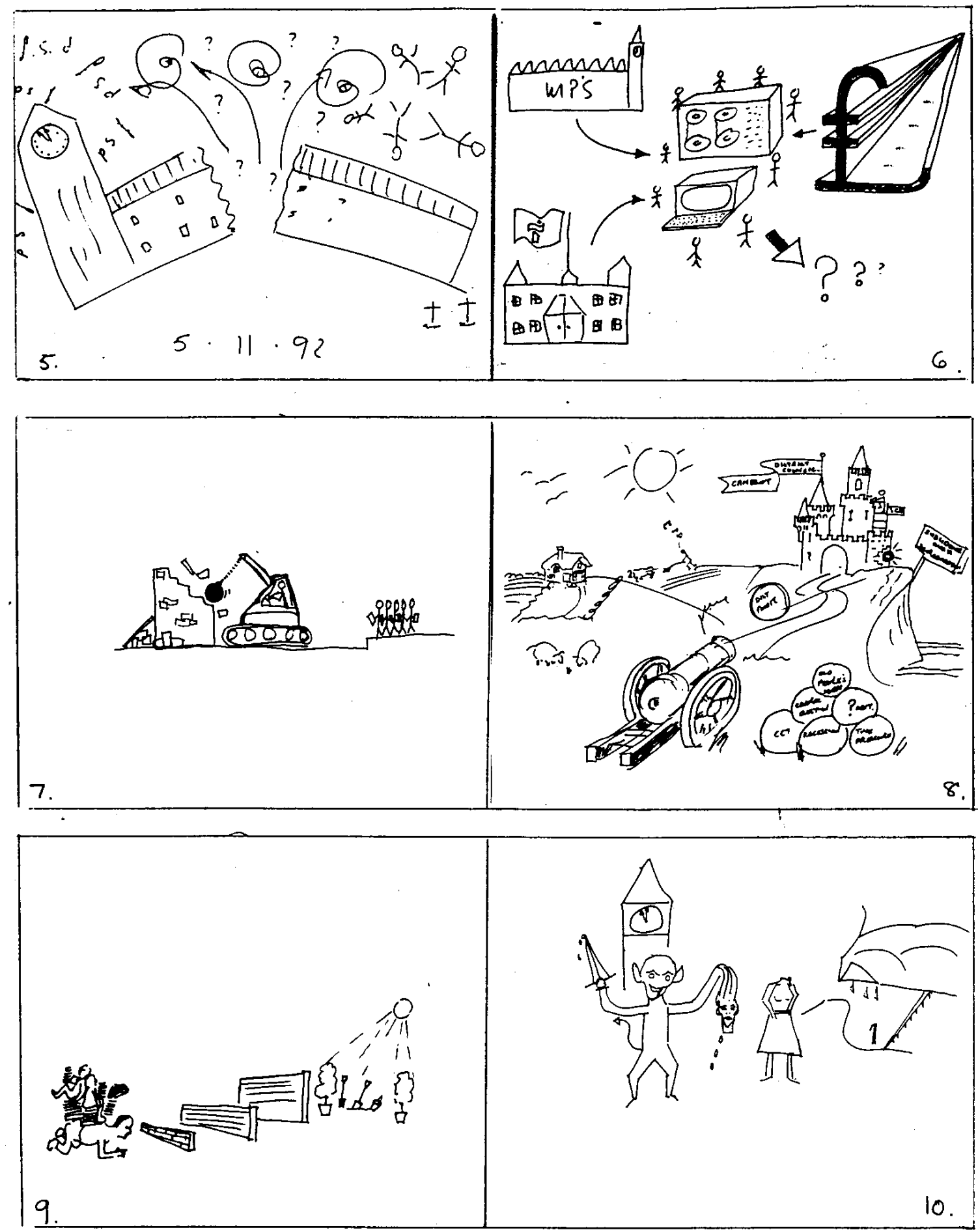

Figure 1: Examples of the manager's drawings from Vince and Broussine's (1996) study. 
The research process for this study was in five stages:

1. The generation of visual data concerning individual feelings about change: Participants were asked to "draw a picture that expresses your feelings about change at work in your organization";

2. Individuals' verbal interpretation of their own drawings: Participants were invited to write on the back of their drawing 'five to ten words or phrases which come to mind when you look at your picture';

3. Team-based reflections on the visual data and the individuals' chosen words: Participants showed their own drawings to the other team members, who then said what meanings they drew from the images. Different layers of data were collected. The team members' interpretations of the images were recorded by the researcher in a field diary. This information was then reviewed by the team to satisfy accuracy. Some overall reflections on the process of the research were collected by the researcher at this stage. The data were collated and reduced in order to provide a focal point for the next stage in the research process.

4. A few weeks after the initial data gathering, inter-group reflections took place involving different hierarchical groups from the same organization. These were between the middle managers and the senior managers involved in the research. Participants in this broader focus group shared the drawings, the individual's own reflections and the original team reflections. These meetings were recorded.

5. Using techniques to promote dialogue, the middle and senior managers undertook a joint synthesis of the data in order to make sense of it for themselves, as well as discussing implications for the organization.

This approach to qualitative research is complicated, multi-layered and risky (much like the change processes and dynamics it was trying to research). The method revealed and captured those aspects of change that rarely surface, but are invariably present. For example, the drawings drew out the complexities and uncertainties involved in change processes. They helped to identify the dualities of feelings involved - the optimism and pessimism about change, the 'hope' and the 'hatred' of change that sat side by side in these managers' experience. The managers themselves were surprised by the strength of emotions that surfaced from the drawings. They were both perplexed by and attracted to the perceptions that emerged. Through the drawings they were able to see some of the key factors in the emotional and political relations that undermined change, in particular poor inter-personal communication and difficulties generated around boundary relations.

The emotional and political dynamics underlying change are often the very things that undermine change initiatives in organizations. However, there are also good reasons for making careful decisions about when and where to use such a method as part of a research design. The use of drawings to generate data on emotions in organizations poses ethical questions for the researcher about the depth of engagement being asked of participants (see our discussion below). It is important therefore to make sure that 
the method is well-explained and well-contained. The method has its risks, both in terms of the fears and anxieties that are generated for the researcher and those that are generated for participants. In addition, 'the reliability of drawings in a qualitative research process depends initially on the acceptance that there is such a thing as underlying or unconscious process and that it can be expressed and contained within an image' (Vince and Broussine, 1996: p. 9). In other words, the method is a leap of faith. However, we contend that all interpretive methods are to some extent a leap of faith, they are connected to the expectation that interesting personal, inter-personal and social dynamics are likely to emerge from a qualitative approach.

\section{Example Two: Participant-led photography}

Participant-led photography (PLP) has less of a lineage in organization studies than the use of drawing, although it has firm foundations in health and social care studies through the work of Wang and Burris $(1994 ; 1997)$ who pioneered the term 'photovoice'. As this name suggests, the basic premise is that research participants are provided with a camera and asked to make a set of photographs that literally represents their view of the issue being researched. These photographs then set the agenda for a later qualitative interview with a researcher, where participants explain why they took the pictures and the meaning and significance they hold. There are two key benefits to this, firstly, it is the participant's subjective perspective that is foregrounded, rather than the researcher's assumptions about what might be important; and secondly, using images reduces the reliance on words, meaning the method is particularly suitable for research with people who have language difficulties, children or disadvantaged groups where perceived power differentials might preclude respondents from feeling that they are able to express themselves freely. To our mind, it is this last characteristic that distinguishes photo-voice from PLP. Photo-voice always has an emancipatory agenda whereas PLP does not - although it may do, particularly if utilized from a critical management studies position (Warren 2005b). 
The following example is drawn from Samantha'a investigation into the meaning and significance of people's personal space at work through an exploration of their 'desk clutter' (Warren 2006). Photography is an ideal medium through which to analyse the importance of space since the camera indiscriminately records everything within its 'gaze' when the shutter is pressed, capturing not only the intended subject of the photograph, but also a great deal of contextual information about the scene with it (Collier and Collier 1986; Shortt and Warren 2012). In Samantha's study, 31 individuals working in a 'hot desking' office within the web design department of a global I.T. firm were asked to take pictures of their desks and later 'talk through' the photographs. The study was part of a larger ethnographic investigation into workplace aesthetics (Warren 2005a) and in particular, motivated by Samantha's curiosity as to why, in an office

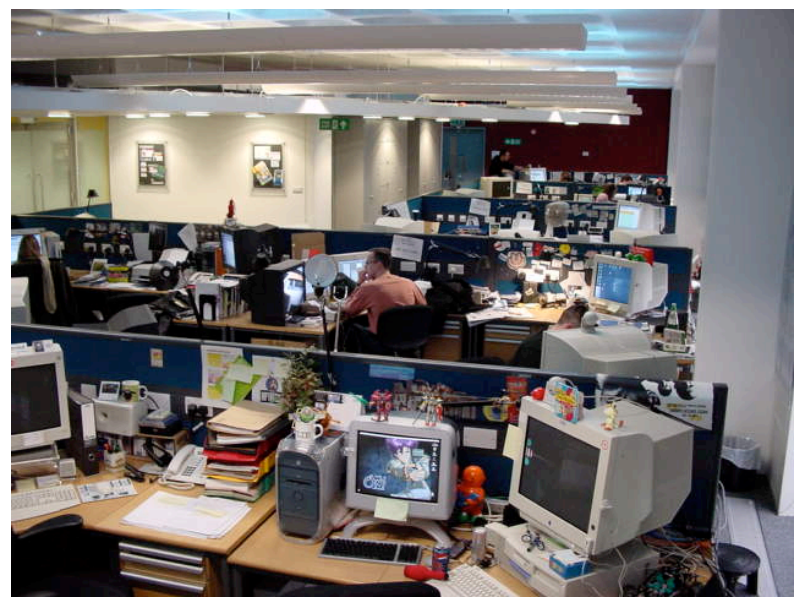
where no-one was supposed to have personal desks, there was such an apparent proliferation of personal effects on display (Figure 2).

Figure 2: The supposed 'hot-desking' space of Dept. $X$

Stages in the research process were as follows:

1. Participants were issued with digital cameras and asked to take one or two photographs of their immediate workspace.

2. The images were downloaded to a laptop for later viewing.

3. The participants were invited to 'talk through' the items depicted in the photographs with the researcher during qualitative interviews. Typical questions included asking about the history and significance of the objects in the photograph and why certain items were displayed on desks and not others.

4. Data was thus generated through the image in the form of the conversations that centred on it, rather than contained in the image itself (Belova 2006).

5. These data were analysed thematically to ascertain the role personalization played for these participants which included 'material anchoring' of emotional and aesthetic ties; a mode of self-expression sometimes used to resist perceived colonization of the individual self by the organization; and collectively to foster a sense of belonging (Warren 2006).

6. The study concluded that efficiency motivated moves towards hot-desking environments may damage employee wellbeing at work. 
The first advantage of using photography was that of 'removed observation'. This research could have been conducted by Samantha physically sitting with the participants at their desks, asking them to talk about the objects apparent there. However, doing this in a busy office was difficult for two reasons: the absence of privacy, which would potentially compromise the richness of data; and noise in the environment which made audio recording of the interview difficult.

It also would be very difficult to do this if the research context was such that employees did not have their own personal space at work, e.g.: hospitality, estates and retail workers, (Shortt 2010 and Betts 2009), or those working remotely such as sales people (Nathan and Doyle 2002). One of the frustrations of handing the camera to the participants, however, was a loss of control of the process. Some participants forgot to do the task, or were late which, on occasion, resulted in frustrating wasted trips to the research site.

The second advantage relates to the 'inventory' function of the camera noted above in that items within the photograph deemed unimportant to the participant can be queried by the researcher. In the following example ${ }^{1}$ (Figure 3), Samantha notices something in the photograph under Simon's desk that he hasn't mentioned, so she asks him about it:

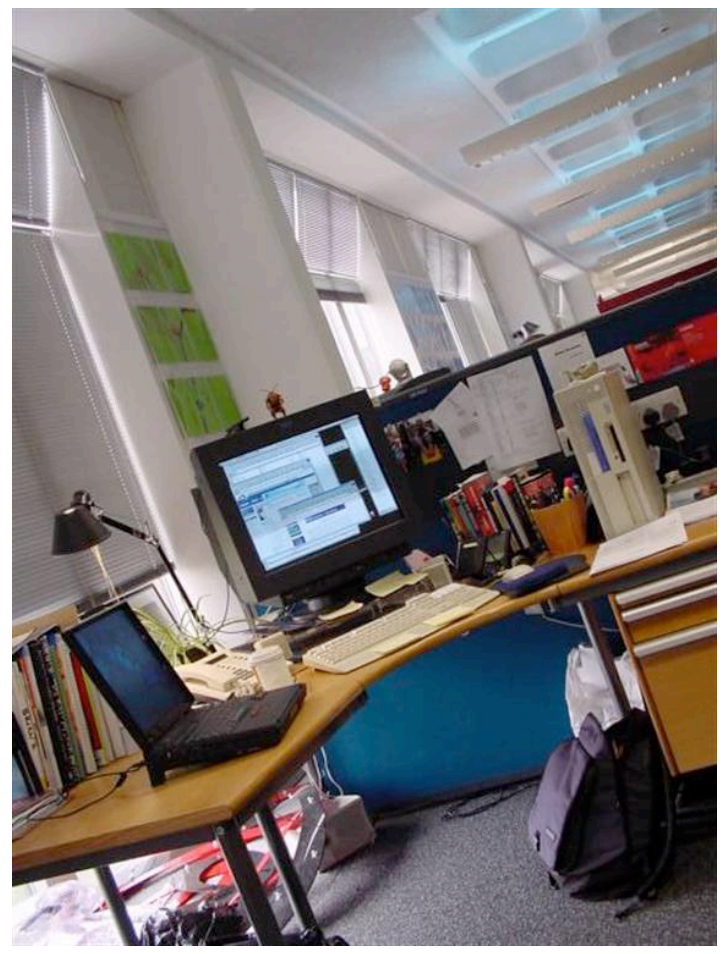

Figure 3: Simon's desk

Samantha: Is that a Scalextric under there? (pointing to the red and black pieces of 'track' in the bottom left of the photograph)

Simon: No, unfortunately not! That's err, more of my mess... as I said I was involved in setting up the [Dept] and at the last moment when we moved in there was a lot of signage to be put up... which we now don't have storage for, so its behind my desk.

Samantha: Is storage a problem then?

Simon: God yes, we have nowhere to put anything but we're supposed to have a, hotdesk... clear desk policy. How's that gonna work?

As the above dialogue shows, important data about the poor practicality of the hotdesking office design would have been lost if Samantha had not been able to see an

\footnotetext{
${ }^{1}$ Simon is a pseudonym to protect the participant's anonymity.
} 
intriguing object captured in the 'inventory' recorded by the camera. The importance of these 'unintended traces' cuts to the heart of the co-creation of data we suggest is a feature of participatory visual methods - data here was generated by the object rather than by the participant, and probed by the researcher in what Belova (2006) calls 'the event of seeing'. This stimulated a further process of reflection by the participant leading to unanticipated threads of discussion.

This leads to the third noteworthy dimension of this method, that quite simply, it generates talk. It speeds rapport and in the study outlined here was reported by participants is being fun to do, securing greater engagement with the project than perhaps might otherwise have been the case. Warren and Parker (2009) refer to this as the 'third party effect' to explain how discussion is always easier when there is something to talk about. It also diffuses potentially uncomfortable personal talk since researcher and participant are not speaking directly to one another. Instead, the conversation flows through the image where attention is focused. Scarles (2010) expands on the significance of this effect by suggesting that the image can act as a point of embodied 'ignition' that unites participant and researcher in contemplation of that which is impossible to put into words (see also Warren 2005b, 2008).

Finally, photography brings the material world into the equation. Although this was an explicit aim of Samantha's study outlined above, the addition of material context in ethnographic research especially is vital to retain some semblance of the richness of how it felt to 'be there' in an aesthetic sense. As Dale and Burrell (2008) argue, the linguistic turn in social research of the 1960's has led to a dematerialization of social research, effectively ignoring how organizational things, objects, places and spaces shape and are shaped by social action. We contend that photography may go some way in addressing this.

\section{Discussion: implications for ethics and analysis in qualitative research}

We have presented two vignettes of participatory visual methods in action and highlighted their respective benefits and drawbacks. Here we consider some of the common issues raised in these examples in relation to what we regard as current challenges within the field of visual organization studies. Firstly, we address the issue of ethics and consider how participatory methods are conducive to robust research ethics practice as well as drawing attention to the ongoing difficulties that the use of the visual' throws up. Secondly, we consider how data generated by the methods outlined above might be analyzed in a way that contributes to furthering good practice in rigorous qualitative research, avoiding charges of superficial 'impressionism' that might otherwise be leveled at the interpretation of visual images. 
A key ethical issue is the extent to which participants continue to consent to take part in the research beyond an initial stage of 'signing the form'. In the case of PLP, this situation is not such a problem since participants retain advance control over what they photograph and choose to reveal to the researcher. More challenging, is obtaining the consent of those who are photographed. How can informed consent be obtained from everyone who inadvertently appears in a picture taken of a busy street scene or retail store for example? Public events tend to display 'disclaimers' asking anyone who is not willing to have their photograph taken to identify themselves to the organizers although we are unsure how exactly the organizers would actually make sure this happened.

In the case of drawing the researcher is not always aware of the emotions that are going to be generated in participant groups (see Vince, 1995b for an example of this). Consent has to be sought from the group or groups that are being engaged in the research, but it is not possible to fully explain what the experience itself may reveal. The act of visualization may trigger unexpected emotional responses. Key to using this approach is for the researcher to be clear that there is an important boundary between drawings that are used in therapeutic interventions (see for example Case and Dalley 2006, Broussine 2008), and drawings used as a research approach to generate data. In the latter, the focal point of the research is not the individual's image, as with art-therapy, but the ways in which imagery from a group depicts underlying emotions and assumptions concerning 'the way we do things here'.

Photography produces an image that is iconographic in its resemblance to the reality it was intended to represent. Consequently, it is important that line managers or other gatekeepers consent to the taking of photographs and care should be taken not to capture iconic identifying features if the organization wishes to remain anonymous. Although no formal guidelines have yet emerged from the visual research community (although see Prosser at al 2008), Samantha's research has always been granted institutional ethical approval by asking participants to sign up to undertake 'responsible photography' (see Appendix One). The visual image is a site of complex copyright laws, governing the right to reproduce an artwork, an image already published even when it is seemingly already in the public domain (eg., an advertisement) or has been legitimately purchased. This poses challenges for visual researchers who are using organizationally produced images as their data and wish to reproduce them in published work.

\section{Analysis}

How should participant made images (whether drawn or photographed) be interpreted for the purposes of analysis in qualitative research? As Prosser and Loxley (2008) note, modes of analyzing visual data need further and more detailed attention - a view with which we would concur, although structural approaches to the analysis of 'found' 
images that rest on similar principles to linguistic deconstruction are much more well developed. These date back to Panofsky, Pierce and Barthes who have contributed to our modern understanding of the semiotic analysis of images (see Davison 2009 for a good overview and Schroeder 2002 for a more critically motivated method of visual analysis). More recently, these ideas have been further developed by contemporary authors, for example contributors to van Leeuwen and Jewitt (2001) and Kress and van Leuwen (2006).

There is a dearth of methodological advice on the analysis of participant generated images within the visual studies field. The studies we have presented above show how images can be used to generate textual data from participants, although both approaches begin with a visual method, they also end with a very traditional interview transcript as the participants and researcher discuss the image in words. The relationship between words and images is incredibly complex - photographs and drawings are usually used as illustrative evidence (such as in newspapers or drawings by court reporters) and where they are the sole focus of attention, rarely appear without a caption that (in part at least) anchors their meanings through text. Indeed, the extent to which we can ever make sense of anything, whether visual or any other sensory mode, without language is a moot point (see Mitchell 1994; Scott 1999).

Whilst we do not have space to do justice to these debates here, we nonetheless wish to raise the issue of analysis as a fruitful area for future development by visual organizational scholars. With the above in mind, we briefly outline three possibilities for the development of analytical techniques in participatory visual methods.

Content analysis: What little commentary there is on analyzing participant made images can be found in social-psychology literature and utilizes content analysis to investigate the frequency - and by extension the significance - of certain representational features of images. For example, Ziller's (1990) notion of 'orientations' involves counting the number and types of objects depicted in his participants images and matching them to personality dispositions as measured by psychological tests. Clarke and Holt (2010) categorize the images entrepreneurs used to symbolize their goals broadly on a content analysis basis. The utility of this last example rests less on recording observations to demonstrate significance, and more on the occurrence of patterns as a way to generate themes.

Traditional thematic analysis: It is possible to analyze the verbal discussions generated by PLP and drawing methods using conventional transcripts of their audio recordings, according to any one of a now burgeoning array of coding procedures (see Saldana 2009). In this approach, the visual is useful at the beginning of the research design, but recedes in importance in the later stages. Whilst there is clearly nothing wrong in this, it does seem to us that it is a pity that the images disappear from the analytical frame once they have 'done their job' of generating words. We would advocate that some of the images should, if possible, be published alongside the textual data in order not to 
lose the very richness that image-based research seeks to generate and capture. In Samantha's study (and elsewhere, see Warren 2002, 2005a), and following Mitchell (1994) she has adopted an 'image-text' approach to the presentation of data where the interview quotes used as data, are accompanied by the image they relate to. This goes some way to mediating the reliance on one or the other medium, given the complexity of the image-text nexus we allude to above. However, even this does not really involve analysis of the images as data in their own right as we discuss further below.

A hybrid mode of analysis?: Whilst recognizing that images should not stand alone from the participants' explanations of them, the fact remains that the participants chose particular scenes, images, or objects to depict from a plethora of possibilities and we speculatively suggest that this might be instructive. Are there cultural, gendered or occupational patterns that consciously or unconsciously led the participants toward certain things in their environment more than others for example? Collier (2001: 39) comes closest to fleshing out this idea with his concept of 'open viewing'. He puts forward a 4 step process for viewing a set of photographs together (one imagines spread out on a table in front of the researcher) in order to "look at, 'listen' to its overtones and subtleties, [and] to discover contrasting patterns" and then goes on to suggest that involving the respondent in this process can only help to verify the interpretation. Whilst this still renders the ultimate analysis a textual one, the idea of building 'photo-sets' for participants to compare and contrast the images they use is an intriguing one we would argue and may help to integrate the visual and the verbal in a more holistic and forceful manner.

\section{Conclusions: a personal picture}

In this chapter we have introduced two participatory visual methods and given an overview of their use in organizational research. We have connected these methods to contemporary challenges in visual methodology and qualitative research more generally. The twin agenda we have focused on -ethics and analysis - we consider to be at the centre of this approach to the practice of qualitative research. Research participants involved in this method are far more concerned with the generation of qualitative data than in those who take part in more 'scientific' studies that generate quantitative data. Because of this we believe that they are owed a particular ethical responsibility. In addition, since the validity of the findings we generate through qualitative research is measured on the basis of its plausibility and not against some external measure, we also believe qualitative researchers should be as reflexive about the way we generate those data as possible - both in terms of collecting and analyzing it. Through these two challenges we hope to have provided other researchers with an interesting set of ideas and perhaps, inspiration for their own practice. 
In keeping with this volume's desire to provide reflexive, experiential accounts of 'real' qualitative research practice, we would like to end the chapter by summarizing some of our personal experiences of using visual methods in organizational research.

Firstly, there is always a risk of style over substance. Ask yourself "What data does this visual method help me to obtain that I couldn't otherwise access?" Visual research needs to establish its credibility on soundly argued methodological justification, as our concerns about the lack of analytical reflexivity demonstrate. This said, both of us are eager to see more research in management and organization studies that utilizes this approach. Publishing your own or participant produced images in academic journals is becoming easier - although obtaining permission to use images you do not own the copyright for (especially if they are already published) is not - and journal editors are likely to insist that the author traces and secures permissions for all images he or she wants to reproduce. This can be expensive, time-consuming or indeed, impossible.

While explaining to participants that (e.g.) no artistic ability is required to produce a drawing, the use of images in research may nonetheless produce resistance (individual and organizational). It is not unusual to hear "But I can't draw!" or "I can't take good photos", so it is important to utilize what is produced however it looks. For example, Russ had a participant who put no marks on her paper, yet the blank page was nonethe-less a powerful image to express individual and collective emotions at work. As this example shows, it is likely that you will also lose some control over the process. You have no idea what your participant is going to draw or present you with a photograph of; no idea of how it might be interpreted in context; and little idea if it will be relevant to your research objectives. This is unnerving, but also important if we are trying to do research within the complexities of organizations.

Finally, there are always technical problems, from procuring suitable equipment and instructing participants on how to use it, to having enough file storage in the case of scanned images or digital photographs, right through to accidentally deleting whole folders of pictures (as Samantha has learned to her chagrin!). However, we think that it is always better to be doing research that we enjoy doing. The creative use of images can be fun both for the researcher and the participant. Images add interest and depth of mutual interpretation to what can sometimes be a rather detached process. 


\section{Further reading:}

Broussine, M. (2008) Creative Methods in Organizational Research, London: Sage, Chapter 4.

An overview of the conceptual underpinnings and ethical dilemmas in using drawing in research.

Rose, G. (2007) Visual Methodologies. London: Sage.

In our opinion, the best all round introduction to visual methods in the social sciences.

Warren (2009) 'Visual Methods in Organizational Research' in in A. Bryman and D. Buchanan (eds.) Handbook of Organizational Research Methods, Sage: London, pp. 566 - 582.

Overview of the particular choices available to and challenges faced by visual researchers in the field of organization studies

inVisio: International Network of Visual Studies in Organizations www.in-visio.org Interactive online hub of the network including resources, links and blog on all matters related to visual studies in organization.

\section{References:}

Bagnoli, A. (2009) 'Beyond the standard interview: the use of graphic elicitation and arts-based methods' Qualitative Research, Vol 9 (5) pp. $547-570$

Bell, E. (2008) Reading Management and Organization in Film, London: Palgrave Mac Millan

Bell, E. (2010) 'Ways of Seeing Organizational Death: A Critical Semiotic Analysis of Organizational Memorialization' Visual Studies, forthcoming

Belova, O. 2004, "Organisations And Their Images: An Empirical Exploration Into The Phenomenology Of Visual Experience". Unpublished PhD thesis, University of Essex

Belova, O. (2006) 'The event of seeing: A phenomenological perspective on visual sensemaking'. Culture and Organization, 12 (2), pp. 93-107

Betts, J. (2009) 'Visual Adaptation of Repertory Grids' Presented at the ESRC 'inVisio' Seminar 'Visual Analysis and Interpretive Methods', University of Exeter, $29^{\text {th }}$ May See: http://in-visio.org/activities/visualanalysis/visual-adaptation-of-repertory-grids/

Bolton, A., Pole, C. and Mizen, P. (2001) 'Picture this: researching child workers', Sociology, 35(2): 501-18. 
Borgerson, J. and J. Schroeder (2002) 'Ethical issues of global marketing: avoiding bad faith in visual representation' European Journal of Marketing, Vol 36 (5/6) pp. 570 - 594

Brewis, J and E. Wray-Bliss (2008) 'Re-searching ethics: Towards a more reflexive critical management studies' Organization Studies, Vol 29 (12) pp. 1521 - 1540

Bryans, P. and Mavin, S. (2006) Visual Images: A Technique to Surface Conceptions of Research and Researchers, Qualitative Research in Organizations and Management: An International Journal 1(2): 113-128

Buchanan, D (2001) The Role of Photography in Organization Research: A reengineering case illustration Journal of Management Inquiry Vol. 10 (2): 151 - 164

Case, C. and T. Dalley (2006) The Handbook of Art Therapy, London: Routledge

Cho, C. H. Phillips, J. R. Hageman, A. M. and Patten, D. M. (2009) Media Richness, User Trust and Perceptions of Corporate Social Responsibility, Accounting, Auditing \& Accountability Journal, Vol 22 (6):

Clarke, J. and R. Holt (2010) 'The mature entrepreneur: A narrative approach to entrepreneurial goals' Journal of Management Inquiry, Vol 19 (1) pp. $69-83$

Collier, M. (2001) 'Approaches to analysis in visual anthropology' in T. van Leeuwen and C. Jewitt (eds.) Handbook of Visual Analysis, London: Sage, pp. $35-60$

Collier, J. and Collier, M. (1986) Visual Anthropology: Photography as Research Method, Albequerque: University of New Mexico Press.

Dale, K. \& Burrell, G. (2003) 'An-aesthetics and architecture' in A. Carr \& P. Hancock (eds.) Art and Aesthetics at Work Palgrave: London pp. 155-173

Davison, Jane (2009) 'Icon, iconography, iconology: Visual branding, banking and the case of the bowler hat' Accounting, Auditing and Accountability Journal, Vol 22 (6) pp. $883-906$

Davison, J., and Skerratt, L. (2007) 'Words, Pictures and Intangibles in the Corporate Report', the Institute of Chartered Accountants of Scotland, Edinburgh

Gagliardi, P. (1990) Symbols and Artifacts: Views of the Corporate Landscape. Berlin and New York: de Gruyter. 
Gallo, M. (2002) Picture this: immigrant workers use photography for communication and change, Journal of Workplace Learning, 14(2):49-57.

Gotllib-Conn, L. (2008) 'Ethics policy as audit in Canadian clinical settings' Qualitative Research, Vol 8 (4) pp. 499 - 514

Guthey, E. and Jackson, B. (2005) 'CEO portraits and the authenticity paradox', Journal of Management Studies, Vol 42(5), pp. $1057-82$

Halford, S. (2004) 'Towards a sociology of organizational space' Sociological Research Online, Vol 9 (1) available from http://www.socresonline.org.uk/9/1/halford.html

Hancock, P. (2005) 'Uncovering the semiotic in organizational aesthetics' Organization, 12(1):29-50.

Hancock, P. (2008) 'Fear and (self)loathing in Coleridge Close: Management in crisis in the 1970's sitcom' Organization, Vol 15 (5) pp. $685-703$

Harper, D. (1984) 'Meaning and work: a study in photo elicitation' International Journal of Visual Sociology, 2(1):20-43.

Holliday, R. (2000) We've Been Framed: visualising methodology. Sociological Review: $504-521$

Hutton, J., Bazalgette, J. and Reed, B. (1997) 'Organization-in-the-mind' In J. Neumann, K. Kellner and A Dawson-Shepherd (Eds.) Developing Organizational Consultancy, London: Routledge.

Jackson, N. \& Carter, P. (2000) 'An-aesthetics' in S. Linstead \& H. Höpfl (eds.) The Aesthetics of Organization Sage: London pp. $180-196$

Kearney, K. S and Hyle, A. E. (2004) Drawing out emotions: the use of participantproduced drawings in qualitative research. Qualitative Research 4/3: 361 - 382.

Kivinen, N. (2006) Entering Organizations: Essays on Image, Space and Difference. Finland: Abo Akademi Turku.

Kress, G. and T. van Leeuwen (2006) Reading Images: The grammar of visual design, London: Routledge

McDonald, P. (2009) 'We just make the pictures...?' How work is portrayed in children's feature length films' Culture and Organization, Vol 15 (1) pp. 21 - 38 
Meyer, A.D (1991) Visual Data in Organizational Research. Organization Science 2/2: 218 - 236.

Morgan, M., Mclnerney, F., Rumbold, J., and P. Liamputtong (2009) 'Drawing the experience of chronic vaginal thrush and complementary and alternative medicine' International Journal of Social Research Methodology, Vol 12 (2) pp. 127 - 146

Mitchell, J. (1994) Picture Theory. Chicago: University of Chicago Press.

Nathan, M and J. Doyle (2002) The State of the Office: The politics and geography of working space London: The Industrial Society

Prosser, J. (ed.) (1998) Image-Based Research: A Sourcebook for Qualitative Researchers. London: Falmer Press

Prosser, J. and A. Loxley (2008) 'Introducing Visual Methods' National Centre for Research Methods Review Paper No. 10 available at http://eprints.ncrm.ac.uk/420/ last accessed $23^{\text {rd }}$ April 2010

Prosser, J., Clark, A. and R. Wiles (2008) 'Visual research ethics at the crossroads' Realities Working Paper Series No. 10 available at http://www.socialsciences.manchester.ac.uk/realities/publications/workingpapers/102008-11-realities-prosseretal.pdf last accessed 23rd April 2010

Saldana, J. (2009) the Coding Manual for Qualitative Researchers, Sage: London

Scarles, C. (2010) 'Where words fail, visuals ignite: Opportunities for visual autoethnography in tourism research' Annals of Tourism, in press doi:10.1016/i.annals.2010.02.001

Schroeder, J. (2002) Visual Consumption, London: Routledge.

Scott. C. (1999) The Spoken Image: Photography and Language. London: Reaktion Books.

Shortt, H. (2010) The Hair Salon - Constructions of Space and Identity, unpublished PhD thesis, University of Bath, UK

Shortt, H. \& S. Warren (2012) Hairdressers: Visual Narratives of Identity in an Iconic Profession Visual Studies, forthcoming

Sievers, B. (2008) 'Perhaps it is the role of pictures to get in contact with the uncanny: The social photo-matrix as a method to promote understanding of the unconscious in organizations' Organization and Social Dynamics, Vol 8 (2) pp. $234-254$ 
Stiles, D.R. (2004) Pictorial Representation. In C. Cassell and G. Symon (Eds.) Essential Guide to Qualitative Methods in Organizational Research, London: Sage.

Strangleman, T. (2004) Ways of (not) seeing work: the visual as a blind spot in WES? Work, Employment and Society 18/1: 179 - 192.

Strangleman, T. (2008) 'Representations of labour: visual sociology and work' Sociology Compass, Vol 2 (5) pp. $1491-1505$

Strangleman, T. (2009) 'Negotiating Organizational Power: The politics of visual research' paper presented to the ESRC inVisio Seminar Series University of Bath, October

van Leeuwen, T. and C. Jewitt (eds.) (2001) Handbook of Visual Analysis, London: Sage,

Vince, R. (1995a) Working with emotions in the change process: using drawings for team diagnosis and dev elopement. Organisations \& People 2/1: $11-17$.

Vince, R. (1995b) Emphasizing learning in management research. Management Learning, 26/ 1: 55-71.

Vince, R. and Broussine, M. (1996) Paradox, Defence and Attachment: Accessing and working with emotions and relations underlying organizational change. Organization Studies, 17/1: 1-21.

Wang, C. and Burris, M.A. (1994) Empowerment through photo novella: portraits of participation, Health Education Quarterly, 21(2): 171-86.

Wang, C. and Burris, M.A. (1997) Photovoice: concept, methodology and use for participatory needs assessment, Health and Behaviour, 24(3): 369-87.

Warren, S. (2002) 'Show me how it feels to work here: Using photography to research organizational aesthetics' ephemera: theory and politics in organizations, Vol 2(3) pp $224-245$

Warren, S. (2005a) Consuming Work: An exploration of organizational aestheticization, unpublished PhD thesis, University of Portsmouth, UK

Warren, S. (2005b) 'Photography and Voice in Critical Qualitative Management Research' Accounting, Auditing and Accountability Journal Vol 18 (6) pp. 861 - 882

Warren, S. (2006) 'Hot Nesting? A visual exploration of personalised workspaces in a 'hot-desk' office environment' in P. Case, S. Lilley \& T. Owens (eds.) The Speed of Organization, Copenhagen Business School Press, pp. $119-146$ 
Warren, S. (2008) 'Empirical challenges in organizational aesthetics research: towards a sensual methodology' Organization Studies, Vol 19 (4) pp. $559-580$

Warren, S. (2009) 'Visual Methods in Organizational Research' in A. Bryman and D.

Buchanan (eds.) Handbook of Organizational Research Methods, Sage: London, pp. 566 $-582$

Warren, S. \& L. Parker (2009) Beancounters or bright young things? Towards the visual study of identity construction among professional accountants. Qualitative Research in Accounting and Management, Vol 6 (4) pp. 205 - 223

Warren, S. \& Fineman., S. (2007) Don't get me wrong but... ambivalence and paradox in a 'fun' work environment in C. Rhodes \& B. Westwood (eds.) Humour, Organization and Work, Routledge: London, pp. $92-112$

Williamson, J. (1978) Decoding Advertisements: Ideology and Meaning in Advertising. London: Boyars.

Wood, M. and Ladkin, D. (2007) 'The event's the thing: encounters with the leaderful moment'. Paper presented to 25th Standing Conference on Organizational Symbolism, Ljubljana, Slovenia.

Wray-Bliss, E. (2003), "A right to respond? Monopolisation of 'voice' in CMS", Ephemera: Theory \& Politics in Organizations, Vol. 4 No. 2, pp. 101-20

Zuboff, S. (1988) In the Age of the Smart Machine: The Future of Work and Power. New York: Basic Books.

Ziller, R. (1990) Photographing the self: Methods for observing personal orientations, Sage: Newbury Park, CA 
Appendix One: example of brief given to research participants taking photographs

\section{Responsible photography}

Taking pictures can be a personal thing - please ask any people who are the subjects of your photographs for permission to show them to us (either before or after you take the picture).

You might also need to take care not to photograph anything which invades another person's privacy or contravenes your organizations' confidentiality policy (for example, visible contents of documents or computer screens). Rest assured, that we can digitally obscure any identifying features of people or the company (eg: faces, company logos etc) and you will be given full opportunity to have any of the pictures we discuss deleted. In fact we will ask you for permission to use each individual picture in any articles or books resulting from the research during our 'interview' meeting, so you will be in full control at every stage.

Other than these common sense precautions, feel free to take the camera anywhere and everywhere for a few days to help you remember to use it. We hope you will enjoy taking part in the research and look forward to seeing the pictures you take.

Once again, we'd like to thank you for agreeing to help us with this important study, if you have any questions at all about the research at any stage, please do not hesitate to contact us on XXX

Kind regards,

\section{Sam Warren}

